\title{
Antioxidant extract counteracts the effects of aging on cortical spreading depression and oxidative stress in the brain cortex ${ }^{1}$
}

Mariana Séfora Bezerra Sousa', lasmym Melissa Soares de Holanda", Heloísa Mirelle Costa Monteiro', Ângela Amâncio-dos-Santos ${ }^{\prime \prime \prime}$

'Fellow PhD degree, Postgraduate Program in Nutrition, Department of Nutrition, Center for Health Sciences, Universidade Federal de Pernambuco (UFPE), Recife-PE, Brazil. Intellectual, scientific, conception and design of the study; acquisition, analysis and interpretation of data; technical procedures; statistical analysis; manuscript writing; final approval.

"Graduate student, Department of Physiology and Pharmacology, Biosciences Center, UFPE, Recife-PE, Brazil. Acquisition of data, technical procedures.

I'PhD, Associate Professor, Department of Physiology and Pharmacology, Biosciences Center, UFPE, Recife-PE, Brazil. Intellectual, scientific, conception and design of the study; acquisition, analysis and interpretation of data; statistical analysis; manuscript writing; critical revision; final approval.

\section{Abstract}

Purpose: To investigate the effects of Murici extract on the brain excitability-dependent phenomenon known as cortical spreading depression (CSD) and on brain oxidative stress.

Methods: Adult and aged Wistar rats were supplemented with murici extract $(150 \mathrm{mg} / \mathrm{kg} /$ day or $300 \mathrm{mg} / \mathrm{kg} /$ day) by gavage for fifteen days. Afterwards, the animals were submitted to a CSD electrophysiological recording and to brain oxidative stress evaluation.

Results: Our results showed that aging decreased CSD propagation velocity, catalase activity and glutathione/oxidized glutathione ratio (GSH/GSSG) in the brain cortex of the rats, and increased malondialdehyde (MDA) concentrations and superoxide dismutase (SOD) activity. The highest dose (300 mg/kg/day) of murici extract accelerated CSD, whereas the lowest $(150 \mathrm{mg} / \mathrm{kg} /$ day) decelerated, in both adult and aged animals. In contrast, aged animals supplemented with murici extract in both doses presented low MDA levels and high GSG/ GSSG ratio in comparison to the control-aged animals.

Conclusion: Murici extract supplementation seems to revert detrimental effects in aged brains and could be considered as a strategy in the treatment of pathologies related to aging and cortical spreading depression.

Key words: Antioxidants. Oxidative Stress. Aging. Rats. 


\section{Introduction}

Aging is a natural and physiological process, but it is also associated with a high occurrence of metabolic and neurodegenerative disorders. Oxidative stress stands out among the key elements involved in these complications ${ }^{1}$. The increase of free radicals and the deterioration of the antioxidant defenses are responsible for most of the damage to DNA, lipids and proteins, which build up and lead to mutation and cellular death $^{2}$. In addition, brain oxidative stress is one of the main factors responsible for cognitive decline in elderly, leading to a reduction of quality of life ${ }^{3}$.

The brain is especially susceptible to oxidative damage imposed by reactive oxygen species (ROS). It has high concentrations of poli-unsaturated fatty acids, requiring a high amount of oxygen to produce energy, but it is deficient, relatively, in antioxidants ${ }^{4}$.

Thus, dietetic antioxidant intake is a useful strategy to increment the antioxidant potential of the body and reduce oxidative damage. These substances complement the endogenous antioxidant action and create a cooperative network of antioxidants, improving the neurological abnormalities related to aging.

Murici(Byrsonimacrassifolia (L.) Kunth), a fruit grown in the regions of the Amaerica, is a source of antioxidant compounds $s^{5}$. Our work evaluated the effect of murici antioxidant extract on the oxidative status of brain cortex and on its electrophysiology through cortical spreading depression (CSD).

CSD is an excitability-related neural response. It is described as a slowly propagating wave of depression of spontaneous neuronal activity. CSD is elicited by electrical, mechanical or chemical stimulation of one point on brain tissue, from which it spreads concentrically to remote cortical regions ${ }^{6}$. This phenomenon is reversible and the brain recovery process from CSD is completed $5-10$ min after being evocated, rendering the brain tissue prone to another CSD. This has been demonstrated in the central nervous system of laboratory animals ${ }^{7}$ and also in the human brain ${ }^{8}$. There are a number of reports showing that CSD seems to be involved in various pathophysiological events with clinical importance for humans including ischemia, migraine and epilepsy ${ }^{7,8}$. Measuring CSD velocity of propagation along the cortical tissue is a reasonable and easy way of estimating the brain susceptibility to CSD.

Previous investigations found that aging impairs the velocity of CSD propagation in brain ${ }^{9}$. Researchers have suggested this is due to an increase in free radicals in the cortical tissue. However, treatment with antioxidants has different effects depending of dosage ${ }^{10}$ or the type of stress imposed to the brain. This work aimed to investigate the effects of two doses of murici extract on CSD and on the oxidative status of the cortex brain both in adult or aged rats. We demonstrated that supplementation with murici extract exerted a dual effect on CSD and reduced oxidative damage in elderly rats.

\section{- Methods}

All experimental procedures had been previously approved by the Institutional Ethics Committee for Animal Research (approval protocol $\mathrm{n}^{\circ}$ 23076.020868/2014-51), whose norms comply with those established by National Institutes of Health Guide for Care and Use of Laboratory Animals (Bethesda, MD, USA).

Adult (90 to 120 days old) and aged (600 to 700 days old) male Wistar rats were housed under controlled temperature $\left(22 \pm 1^{\circ} \mathrm{C}\right)$ and photoperiodic (12:12 h night/day cycle) conditions, with free access to food (PresenceEvialis ${ }^{\circ}$ ) and water. 


\section{Murici extract}

Dried and powdered murici fruit (20g) was submitted to three consecutive extractions in acetone $(100 \mathrm{~mL})$ at room temperature $\left(25^{\circ} \mathrm{C}\right)$ for 30 minutes. After agitation, the samples were filtered through qualitative filter paper. In order to obtain the murici extract as powder, acetone was removed by using a rotary evaporator under reduced pressure, at $30^{\circ} \mathrm{C}$. These extracts were kept at $-20^{\circ} \mathrm{C}$. Later, the animals received this murici extract powder. The powder had been weighed and reconstituted in a solution of $0.5 \%$ carboxymethylcellulose (CMC) and $10 \%$ soybean oil. This solution used to dissolve murici extract powder was called as vehicle.

Antioxidant compounds found in the murici extract are shown in Table 1 . They include ascorbic acid, total carotenoids, total polyphenols, gallic acid and quercetin. Ascorbic acid was analyzed by the Tilman method, based on the reduction of the sodium salt 2,6-dichlorophenol indophenol (DCFI) by ascorbic acid ${ }^{11}$. Total carotenoids were quantified by UV-visible spectrophotometry, according to Rodriguez-Amaya ${ }^{12}$. The carotenoid concentration was calculated by using the following formula: $Q=(O D \times V) / E$, where $\mathrm{Q}$ denotes carotenoids amounts (g); OD stands for optical density (445 nm); $V$ is the volume $(\mathrm{mL})$; and $E=2480$ (lutein specific extinction coefficient). The total phenolics were determined by the Folin Ciocalteau method ${ }^{13}$. The total phenolic content was expressed as milligrams of gallic acid equivalent (GAE) per gram of the extract. Quercetin and gallic acid were identified and quantified by a modified version of the method described by Porgali and Byuktuncel ${ }^{14}$. This uses HPLC with UV/Vis detection and a reversed-phase Acclaim 120 Dionex C-18 column ( $250 \mathrm{~mm} \times 4.6 \mathrm{~mm}, 5 \mu \mathrm{m})$. The mobile phase consisted of $1 \%$ formic acid (A) and metanol (B). The flow rate was 0.5
$\mathrm{mL} / \mathrm{min}$ and the injection volume was $20 \mu \mathrm{L}$. The peaks were identified by comparing their retention times with those of the standard ones (Sigma Aldrich, St Louis, MO, USA). Quercetin and gallic acid calibration curves were used for quantification.

Table 1 - Antioxidant compounds of murici extract.

\begin{tabular}{lc}
\hline Antioxidant compounds & $\begin{array}{c}\text { Concentration* } \\
\text { (mg/g extract) }\end{array}$ \\
\hline Ascorbic acid & $0.24 \pm 0.03$ \\
Total carotenoids & $0.57 \pm 0.02$ \\
Total phenolics & $8.36 \pm 0.54$ \\
Gallic acid & $0.22 \pm 0.04$ \\
Quercetin & $1.29 \pm 0.23$ \\
\hline
\end{tabular}

*Means \pm standard deviation. Values are means of duplicate measurements.

\section{Treatment with murici extract}

Adult and aged animals received murici extract, by gavage, during 15 days. The extract was administered in doses of $150 \mathrm{mg} / \mathrm{kg} /$ day or $300 \mathrm{mg} / \mathrm{kg} /$ day. Control animals received an equivalent volume $(1 \mathrm{~mL} / \mathrm{kg})$ of the vehicle solution $(0.5 \%$ carboxymethylcellulose and $10 \%$ soybean oil).

The animals were divided into six groups according to the age and the dosage of murici extract they received: 1 ) adult control (vehicle solution, $n=10) ; 2$ ) adult plus murici 150 (150 $\mathrm{mg} / \mathrm{kg} /$ day of extract, $\mathrm{n}=10)$; 3) adult plus murici $300(300 \mathrm{mg} / \mathrm{kg} /$ day of extract, $\mathrm{n}=10)$; 4) aged control (vehicle solution, $n=8$ ); 5 ) aged plus murici $150(150 \mathrm{mg} / \mathrm{kg} /$ day of extract, $\mathrm{n}=$ $10) ; 6)$ aged plus murici $300(300 \mathrm{mg} / \mathrm{kg} /$ day of extract, $n=10$ ). The next day after the last murici administration, each animal was submitted to a CSD electrophysiological recording. 


\section{Cortical spreading depression recordings}

Firstly, animals were anesthetized, intraperitoneally, with a mixture of $1000 \mathrm{mg} /$ $\mathrm{kg}$ urethane plus $40 \mathrm{mg} / \mathrm{kg}$ chloralose (Sigma Co., USA). A tracheal cannula was inserted to facilitate breathing. Three trephine holes (2-4 $\mathrm{mm}$ in diameter) were made on the right side of the skull, parallel to the midline. The first hole (in the frontal bone) was used to apply the stimulus to elicit CSD. The other two holes (on the parietal bone) were used to record the propagating CSD wave. During the recording sessions, rectal temperature was continuously monitored and kept at $37 \pm 1^{\circ} \mathrm{C}$.

CSD was elicited at 20-min intervals by applying, for 1-min, a cotton ball (1-2 $\mathrm{mm}$ in diameter) soaked in $2 \% \mathrm{KCl}$ solution (approximately $270 \mathrm{mM}$ ) to the hole drilled at the frontal region. On the two parietal holes, the slow DC-potential change was recorded for 4 hours using a pair of $\mathrm{Ag}-\mathrm{AgCl}$ agar-Ringer electrodes (one in each hole) against a common reference electrode of the same type, placed on the nasal bones. Electrodes were connected to a digital data acquisition system (EMG Systems, Sao Paulo, Brazil). CSD velocity of propagation was calculated based on the time required for a CSD wave to travel the distance between the two cortical electrodes and it was expressed in $\mathrm{mm} / \mathrm{min}$.

\section{Brain tissue preparation}

After finishing the recording sessions, the still-anesthetized animals were decapitated. The brains were removed rapidly and rinsed in ice-cold saline. Then, the cerebral cortex was isolated and was homogenized in cold extraction buffer (50 mM Tris base, $\mathrm{pH}$ 7.4; 1 mM EDTA; 2 mM phenylmethylsulfonyl fluoride, and $1 \mathrm{mM}$ sodium orthovanadate) and centrifuged for $10 \mathrm{~min}$ at $1000 \times \mathrm{G}$ at 4 으. The supernatants were stored at -80 으 for the analysis of oxidative stress. The oxidative stress measurements were carried out in triplicate. The protein content of the homogenates was determined with Bradford reagent ${ }^{15}$.

\section{Lipid peroxidation measurement}

Lipid peroxidation levels were measured according to Ohkawa et al. ${ }^{16}$ In this method, the quantification of lipid peroxidation products is performed based on the formation of substances reacting with thiobarbituric acid (TBA), or the final products of lipid peroxidation, e.g., malondialdehyde (MDA). In this assay, the reaction was performed with a solution of $8.1 \%$ sodium dodecyl sulfate, $20 \%$ acetic acid and $0.8 \%$ thiobarbituric acid. To perform the calculations, a standard curve of 1,1,3,3-tetramethoxypropane was made. Measurement was performed spectrophotometrically at $532 \mathrm{~nm}$ by using a plate reader (Thermo Scientific, Varioskan flash spectral scanning multimode reader). The results were expressed in $\mathrm{nM}$ equivalents of $\mathrm{MDA} / \mathrm{mg}$ protein.

\section{Total superoxide dismutase activity (SOD)}

The activity of superoxide dismutase (SOD) was evaluated according to Misra and Fridovich $^{17}$ at $25^{\circ} \mathrm{C}$. The reaction medium was composed of $0.05 \mathrm{M}$ carbonate buffer $(\mathrm{pH}$ 10.2) and $150 \mathrm{mM}$ epinephrine. Absorbances were read every 15 seconds for 2 minutes at $480 \mathrm{~nm}$. The results were expressed as units per milligram of protein (U/mg protein), where each unit represents the amount of enzyme that causes $50 \%$ inhibition of epinephrine oxidation.

\section{Catalase activity (CAT)}

In order to evaluate catalase activity (CAT), the reaction medium was composed of $300 \mathrm{mM} \mathrm{H}_{2} \mathrm{O}_{2}$ and $50 \mathrm{mM}$ phosphate buffer 
$(\mathrm{pH} 7.0)$, according to $\mathrm{Aebi}^{18}$ at $22^{\circ} \mathrm{C}$. Using a spectrophotometer, we measured absorbance readings every 10 seconds for 2 minutes at 240 $\mathrm{nm}$. The results were expressed as units per milligram of protein (U/mg protein).

\section{Reduced glutathione (GSH)/oxidized}

glutathione (GSSG) ratio

The levels of GSH and GSSG were analyzed according to Hissin and Hilf ${ }^{19}$ by using a spectrofluorimeter with $350 \mathrm{~nm}$ excitation and $420 \mathrm{~nm}$ emission. The results were expressed in $\mathrm{nM}$ of GSH and GSSH per mg of protein by using a standard curve of GSH and GSSG, respectively. Based on these results, the GSH/GSSG ratio was calculated.

\section{Statistical analysis}

All data sets are expressed as means \pm standard deviation (SD). Accordingly, statistical significance was analyzed by using a two-way ANOVA followed by post-hoc Holm-Sidak, using GraphPad Prism software version 5.0 for Windows (San Diego, CA, USA). Differences were considered statistically significant when $p$ $<0.05$.

\section{- Results}

CSD propagation velocity following treatment with murici extract

Electrophysiological CSD recordings (slow DC potential change) of three adult rats and three aged rats of the experimental groups (control, MUR-150 and MUR-300) are shown in Figure 1 and confirm the presence of CSD after $\mathrm{KCl}$ application. In general, topical application of $2 \% \mathrm{KCl}$ for $1 \mathrm{~min}$ at one point of the frontal cortex in the right hemisphere caused a single CSD wave that propagated without interruption and could be recorded by the two electrodes at the parietal surface of the same hemisphere.

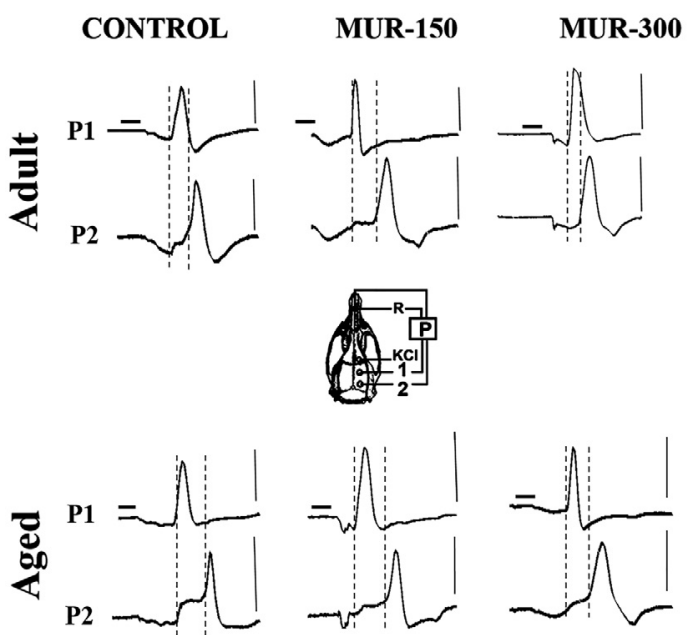

Figure 1 - Electrophysiological recordings (slow potential changes, P) of CSD in rats supplemented with murici extract.

Animals received murici extract (150 $\mathrm{mg} / \mathrm{kg} /$ day, MUR-150; or $300 \mathrm{mg} / \mathrm{kg} /$ day, MUR-300) or vehicle (Control) during 15 days. The vertical solid bars at the right of the traces indicate $10 \mathrm{mV}$ (negative upwards). The horizontal bars on the traces from the recording point 1 (P1) indicate the time (1 min) of stimulation with $2 \% \mathrm{KCl}$ to elicit CSD. Once elicited in the frontal cortex, CSD was recorded by the two cortical electrodes located at the parietal cortex (central skull diagram, points 1 and 2). A third electrode of the same type was placed on the nasal bones and served as a common reference $(R)$ for the recording electrodes. The vertical dashed lines indicate the latency of a CSD wave crossing the interelectrode distance.

ANOVA showed significant differences on CSD propagation velocity between the adult and aged groups when both were supplemented with murici extract ( $F[5,639]$ $=1889.38 ; \mathrm{p}<0.05)$. Post-hoc comparisons 
revealed a significant decrease in CSD velocity in the aged control animals compared to the adult control animals. At both ages, the rats treated with the highest dose of murici extract (300 $\mathrm{mg} / \mathrm{kg} /$ day) presented the highest CSD velocities compared to the corresponding control groups, whereas the lowest dose (150 $\mathrm{mg} / \mathrm{kg} /$ day) decelerated CSD (Table 2).

Table 2 - CSD velocity of propagation in adult rats (90-120 days old) and aged rats (600-700 days old).

\begin{tabular}{lcc}
$\begin{array}{l}\text { Experimental } \\
\text { groups }\end{array}$ & \multicolumn{2}{c}{ CSD velocity $(\mathrm{mm} / \mathrm{min})$} \\
Control & $3.62 \pm 0.22$ & $2.54 \pm 0.11$ \\
MUR-150 & $2.65 \pm 0.23^{\mathrm{a}}$ & $2.24 \pm 0.08^{\mathrm{a}}$ \\
MUR-300 & $4.46 \pm 0.32^{\mathrm{a}, \mathrm{b}}$ & $3.47 \pm 0.11^{\mathrm{a}, \mathrm{b}}$ \\
\hline
\end{tabular}

Animals received murici extract $(150 \mathrm{mg} / \mathrm{kg} / \mathrm{day}$, MUR-150; or $300 \mathrm{mg} / \mathrm{kg} / \mathrm{day}, \mathrm{MUR}-300$ ) or vehicle (Control) during 15 days. Values are presented as mean \pm standard deviation of the mean.

a $p<0.05$ compared to the corresponding control group.

${ }^{b} p<0.05$ compared to the MUR-150 group of the same age. The asterisk indicates that all the aged groups differ significantly from the corresponding adult group $(p<0.05)$.

\section{Oxidative status of the brain cortex following} the treatment with murici extract

The oxidative status of the brain cortex of adult and aged rats was assessed by measuring malondialdehyde (MDA) levels, GSH levels, glutathione/oxidized glutathione ratio (GSH/ GSSG) and catalase (CAT) and superoxide dismutase (SOD) antioxidant enzymes activity (Figure 2).

By comparing adult and aged control animals, respectively, aged rats showed an increase in the levels of MDA (4.05 \pm 0.69 vs. $6.98 \pm 0.86 \mathrm{nM} \mathrm{MDA} / \mathrm{mg}$ of protein), GSH concentration (56.87 \pm 5.97 vs. $32.11 \pm 3.01$ $\mathrm{nM} / \mathrm{mg}$ of protein), GSH/GSSG ratio (4.64 \pm 0.33 vs. $1.48 \pm 0.07)$. They also presented a reduction in catalase activity $(0.80 \pm 0.19$ vs. $0.47 \pm 0.06 \mathrm{U} / \mathrm{mg}$ of protein) and an increment of the SOD enzyme activity $2.81 \pm 0.44$ vs. 4.67 $\pm 1.21 \mathrm{U} / \mathrm{mg}$ of protein) (Figure 2).

In the adult rats, the treatment with the lowest dose of murici extract $(150 \mathrm{mg} /$ $\mathrm{kg}$ ) did not modify the oxidative status of the brain cortex. In contrast, aged animals supplemented with this dose presented lower levels of MDA and higher GSH/GSSG ratio than the respective aged controls. Values for MDA content and GSH/GSSG ratio in the brain cortex of the murici treated animals vs. the control ones were, respectively, $5.48 \pm 0.80 \mathrm{nM}$ MDA/ $\mathrm{mg}$ of protein vs. $6.98 \pm 0.86 \mathrm{nM} \mathrm{MDA} / \mathrm{mg}$ of protein and $3.89 \pm 0.38$ vs. $1.48 \pm 0.07(p<0.05)$ (Figure $2 \mathrm{~A}, \mathrm{C}$ ). At this dose, the murici extract was not able to modify either GSH level, nor the catalase and SOD activity in the brain cortex of the animals.

Concerning the highest dose (300 $\mathrm{mg} / \mathrm{kg}$ ), ANOVA revealed that murici extract treatment significantly altered the concentrations of MDA in the brain cortex of adult and aged rats ( $F[5.52]=18.134 ; p<0.05)$. In the adults, MDA concentrations were higher in the MUR-300 group (7.31 $\pm 1.60 \mathrm{nM} \mathrm{MDA} /$ $\mathrm{mg}$ of protein) than in its respective control group (4.05 $\pm 0.69 \mathrm{nM}$ MDA/mg protein) ( $p$ $<0.05$ ) (Figure 2A). At this dose, the murici extract also reduced GSH levels (42.54 \pm 11.06 $\mathrm{nM} / \mathrm{mg}$ protein vs. $56.87 \pm 5.97$ in the controls) and GSH/GSSG ratio ( $2.49 \pm 0.13$ vs. $4.64 \pm 0.33$ in the controls) in the brain cortex of the adult rats ( $p<0.05$ ) (Figure $2 C, D)$. In addition, post hoc comparisons showed that murici extract at this dosage inhibited the activity of the enzyme catalase $(0.51 \pm 0.03 \mathrm{U} / \mathrm{mg}$ of protein vs. $0.80 \pm$ 0.19 in the controls) (Figure 2D). Aged animals supplemented with $300 \mathrm{mg} / \mathrm{kg}$ of murici extract had lower levels of MDA (5.13 \pm 1.39 $\mathrm{nM}$ MDA/mg of protein) and higher GSH/GSSG ratio (3.71 \pm 0.25 ) when compared to their aged controls $(p<0.05)$. 
$\mathbf{A}$

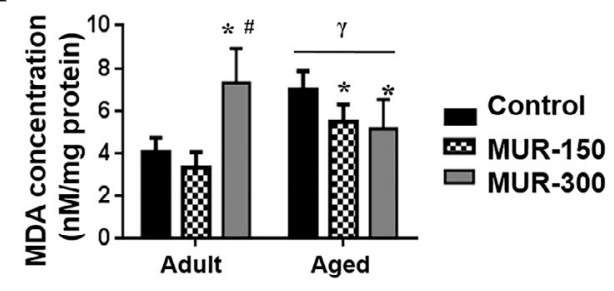

B

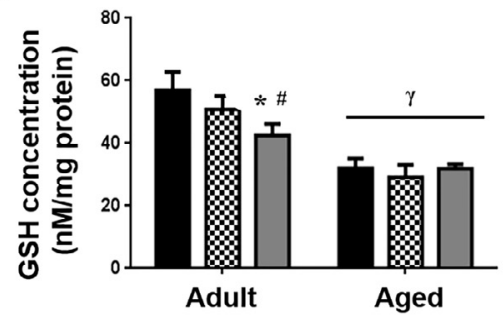

D

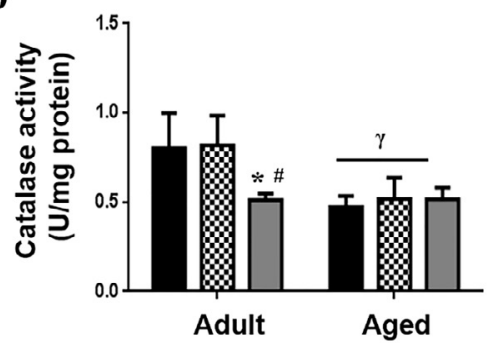

C

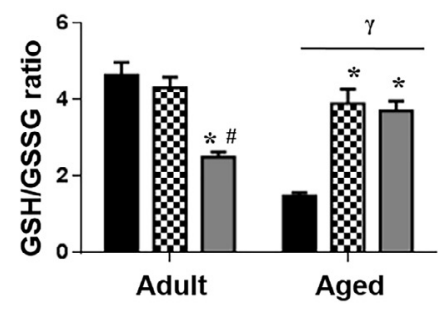

E

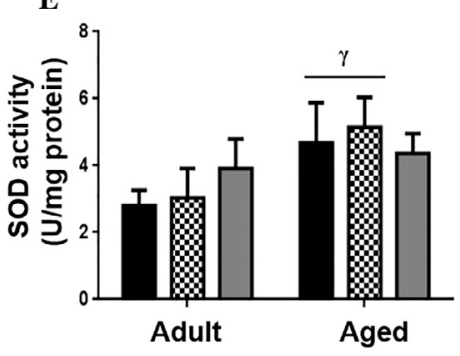

Figure 2 - Oxidative status of the cerebral cortex of adult and aged rats supplemented with murici extract.

Animals received murici extract $(150$ $\mathrm{mg} / \mathrm{kg} / \mathrm{day}$, MUR-150; or $300 \mathrm{mg} / \mathrm{kg} / \mathrm{day}$, MUR-300). Values are presented as mean \pm standard deviation ( $n=6$ to 8 animals per group). A) malondialdehyde (MDA) levels, B) Reduced glutathione levels (GSH), C) Reduced glutathione/oxidized glutathione ratio, D) Catalase enzyme activity (CAT), E) Superoxide dismutase enzyme activity (SOD). ${ }^{*} p<0.05$ compared to the control group of the same age. $\# \mathrm{p}<0.05$ compared to the MUR-150 group of the same age. ${ }^{r} p<0.05$ compared to the corresponding adult group.

\section{Discussion}

In this study, we investigated whether supplementation with murici extract alters brain excitability as indexed by cortical spreading depression (CSD). Murici extract had a differential effect depending on the amount of the supplemented dose, in both adult and aged animals. It promoted a decelerator effect on CSD propagation velocity at the dose of 150 $\mathrm{mg} / \mathrm{kg} /$ day and an accelerator effect when this dose was doubled ( $300 \mathrm{mg} / \mathrm{kg} /$ day).

Murici is an important source of carotenoids ${ }^{5}$ that can act as antioxidants in the brain. On the other hand, free radicals mediate the increase of the neuronal excitability needed to evoke CSD as previously suggested ${ }^{20}$. Here, the lowest dose of the murici extract led to CSD deceleration, which could have been due to its antioxidant properties. The highest dose, on the other hand, facilitated CSD propagation in the brain. 
Interestingly, a well-known antioxidant molecule, ascorbic acid, has demonstrated similar biphasic effects in distinct models of experimental seizures ${ }^{21}$. In addition, Mendesda-Silva et al. ${ }^{10}$ found that ascorbic acid administered in low doses $(30 \mathrm{mg} / \mathrm{kg} / \mathrm{d}$ ) acted as an antioxidant in the brain and decelerated CSD propagation, whereas at the doses of 60 $\mathrm{mg} / \mathrm{kg} / \mathrm{d}$ and $120 \mathrm{mg} / \mathrm{kg} / \mathrm{d}$, it accelerated CSD and had a pro-oxidant effect. Evidence indicates that antioxidant compounds, such as ascorbic acid, carotenoids and polyphenols can produce reactive radical species when they are in high concentrations or in the presence of transition metal ions in the brain ${ }^{22}$. Thus, it is possible that the murici extract acts as a pro-oxidant substance when it is administered at the dosage of $300 \mathrm{mg} / \mathrm{kg}$ for fifteen days, as suggested by the faster CSD propagation.

In the control aged animals, CSD propagation velocity was slower than in the adult control animals. This agrees with previous data ${ }^{9}$. One possibility is that aging induces a redox imbalance, generating an increase in free radicals in the brain, which can interfere with CSD propagation. In our study, murici extract at $150 \mathrm{mg} / \mathrm{kg}$ reduced CSD propagation velocity in the aged rats, as was also seen in the adult animals. However, the highest dose of murici extract $(300 \mathrm{mg} / \mathrm{kg}$ ) normalized CSD values, bringing them close to CSD values of the control adult animals. This suggests that a dose that may be excessive for the brain under control conditions could just be necessary in the presence of a metabolic stressor, i.e. aging.

Thus, it is possible that free radicals are involved in the impairment of aginginduced CSD propagation, since modulation in antioxidant levels influences CSD propagation velocity in elderly animals. However, other signaling pathways could be also involved. For instance, during the aging process, ROS oxidizes calcium and potassium ionic channels and changes the function of some membrane receptors, like NMDA (N-methyl-D-aspartate) receptor, which it is necessary for CSD initiation and propagation ${ }^{23}$. Additionally, aging alters the levels of some neurotransmitters in the brain. Elderly subjects present reduced levels of gamma-aminobutyric acid (GABA) and glutamate in the brain cortex ${ }^{24}$. These two neurotransmitters are involved in CSD neuroexcitability. Further studies are necessary to understand fully aging-induced electrophysiological brain changes.

The mechanisms by which murici extract affects CSD propagation are not completely known. However, we suggest that the decelerator effect on CSD could be due its bioactive compounds. Murici extract is rich in antioxidant substances such as carotenoids and polyphenols (Table 1). Concerning the carotenoids in murici fruit, the xanthophylls such as lutein and zeaxanthin represent 94\% of the total, and among the polyphenols, quercetin is the prevailing ${ }^{5}$.

The lutein can be accumulated in the myelin sheath and improve its structural integrity, maintaining adequate communication between neurons ${ }^{25}$. In fact, lutein is linked to adequate axon myelination. This is worth considering, since there is an inverse correlation between myelin content and CSD propagation ${ }^{26}$.

The antioxidant role of quercetin is well established. It acts as a powerful electron giver to the ROS, sequestering the hydrogen peroxide. Quercetin acts also as a chelator of oxidant metals and increases GSH levels, through the activation of the transcription factor "Nuclear factor-E2-related factor" $(\mathrm{Nrf2})^{27}$. Moreover, quercetin can restore serotonin levels in the rat's brain ${ }^{28}$. Serotonergic neurons are very important for stabilizing the delicate equilibrium between excitatory and inhibitory neuronal influences that determine cortical excitability and CSD propagation. Some 
data suggest that cortical serotonergic activity negatively modulates CSD propagation in the rat cortex ${ }^{29}$.

In the present study, the aged control rats exhibited an elevation in SOD activity, which indicates an increase in superoxide production, and a decrease in CAT activity. In addition, there was an increase in glutathione peroxidase activity together with a low GSH/ GSSG ratio. All of these indicate a possible accumulation of hydrogen peroxide in the brain cortex. This promotes oxidative damage, as denoted by the increase in MDA levels in those animals. However, the murici extract treatment counteracted aging-induced redox imbalance, since it enabled an increase in GSG/ GSSG and a decrease in MDA levels. PerezGutierrez et $a l^{30}$, found a similar antioxidant effect of murici extract at the dose of $300 \mathrm{mg} /$ $\mathrm{kg} /$ day in diabetic rats.

In adult animals, the lowest dose of murici extract did not change the oxidative status of the brain. However, the highest dose impaired cortex oxidative balance. As mentioned above, high doses of antioxidant compounds may exert a pro-oxidant effect on the brain ${ }^{22}$. This reinforces the idea that antioxidant supplementation seems to have a protective role under metabolic stress conditions, but could be harmful if the brain is under standard conditions.

\section{Conclusion}

Murici extract supplementation seems to revert detrimental effects in aged brains and could be considered as a strategy in the treatment of pathologies related to aging and cortical spreading depression.

\section{References}

1. Harman D. Aging: a theory based on free radical and radiation chemistry. J Gerontol.
1956;11(3):298-300. doi: 10.1093/ geronj/11.3.298.

2. Zhao $Y$, Zhao B. Oxidative stress and the pathogenesis of Alzheimer's disease. Oxid Med Cellular Longev. 2013;2013:316523. doi: $10.1155 / 2013 / 316523$.

3. Baierle $\mathrm{M}$, Nascimento SN, Moro AM, Brucker N, Freitas F, Gauer B, Durgante $\mathrm{J}$, Bordignon $\mathrm{S}$, Zibetti $\mathrm{M}$, Trentini CM, Duarte MM, Grune T, Breusing N, Garcia SC. Relationship between inflammation and oxidative stress and cognitive decline in the institutionalized elderly. Oxid Med Cell Longev. 2015;2015:804198. doi: 10.1155/2015/804198.

4. Bradbury J. Docosahexaenoic acid (DHA): an ancient nutrient for the modern human brain. Nutrients. 2011;3(5):529-54. doi: 10.3390/nu3050529.

5. Mariutti LRB, Rodrigues E, Mercadante AZ. Carotenoids from Byrsonima crassifolia: identification, quantification and in vitro scavenging capacity against peroxyl radicals. J Food Composition Analysis 2013;31:15560. doi: 10.1016/j.jfca.2013.05.005.

6. Leao AAP. Spreading depression of activity in the cerebral cortex. J Neurophysiol. 1944;7(6):359-90. doi: 10.1152/ jn.1944.7.6.359.

7. Gorji A. Spreading depression: a review of the clinical relevance. Brain Res Rev. 2001;38 (1-2):33-60. PMID: 11750926.

8. Dohmen C, Sakowitz OW, Fabricius $M$, Bosche B, Reithmeier T, Ernestus RI, Brinker G, Dreier JP, Woitzik J, Strong AJ, Graf R. Spreading depolarizations occur in human ischemic stroke with high incidence. Ann Neurol. 2008;63(6):720-8. doi: 10.1002/ ana.21390.

9. Guedes RC, Amorim LF, Teodósio NR. Effect of aging on cortical spreading depression. Braz J Med Biol Res. 1996;29(10):1407-12. PMID: 9181117.

10.Mendes-da-Silva RF, Lopes-de-Morais AA, Bandim-da-Silva ME, Cavalcanti $G$ de $A$, Rodrigues AR, Andrade-daCosta BL, Guedes RC. Prooxidant versus antioxidant brain action of ascorbic acid in wellnourished and malnourished rats as a function of dose: a cortical spreading depression and malondialdehyde analysis. Neuropharmacology. 2014;86:155-60. doi: 10.1016/j.neuropharm.2014.06.027. 
11.Instituto Adolfo Lutz. Métodos físicoquímicos para análise de alimentos. São Paulo: Instituto Adolfo Lutz; 2008. Disponível em: http://www.ial.sp.gov.br/ resources/editorin place/ial/2016_3_19/ analisedealimentosial_2008.pdf

12.Rodriguez-Amaya DB. A guide to carotenoid analysis in food. Washington: Internation Life Sciences Institute; 2001. Available from: http://beauty-review.nl/wp-content/ uploads/2014/11/A-guide-to-carotenoidanalysis-in-foods.pdf

13. Mira NVM, Barros RMC, Schiocchet MA, Noldin JA, Lanfer-Marquez UM. Extração, análise e distribuição dos ácidos fenólicos em genótipos pigmentados e não pigmentados de arroz (Oryza saliva L.). Ciênc Tecnol Aliment. 2008;28(4):994-1002. doi: 10.1590/S0101-20612008000400036.

14.Porgali $E$, Büyüktuncel $E$. Determination of phenolic composition and antioxidant capacity of native red wines by high performance liquid chromatography and spectrophotometric methods. Food Res Int. 2012;45(1):145-54. doi: 10.1016/j. foodres.2011.10.025.

15.Bradford MM. A rapid and sensitive method for the quantitation of microgram quantities of protein utilizing the principle of proteindye binding. Anal Biochem. 1976;72:24854. doi: 10.1016/0003-2697(76)90527-3.

16.Ohkawa H, Ohishi N, Yagi K. Assay for lipid peroxides in animal tissues by thiobarbituric acid reaction. Anal Biochem. 1979;95:3518. doi: 10.1016/0003-2697(79)90738-3.

17.Misra P, Fridovich I. The role of superoxide anion in the autoxidation of epinephrine and a simple assay for superoxide dismutase. J Biol Chem. 1972;247:3170-5. PMID: 4623845.

18.Aebi H. Catalase in vitro. Methods Enzymol. 1984;105:105:121-6. PMID: 4623845.

19. Hissin PJ, Hilf RA. Fluorometric method for determination of oxidized and reduced glutathione in tissues. Anal Biochem. 1976;74:214-26. PMID: 962076.

20.Malkov A, Ivanov Al, Popova I, Mukhtarov M, Gubkina O, Waseem T, Bregestovski P, Zilberter Y. Reactive oxygen species initiate a metabolic collapse in hippocampal slices: potential trigger of cortical spreading depression. J Cereb Blood Flow Metab. 2014;34(9):1540-9. doi: 10.1038/ jcbfm.2014.121.

21.Schneider MO, Furian AF, Royes LFF, Fighera MR, Myskiw JC, Fiorenza NG, Mello CF. Ascorbate modulates pentylenetetrazolinduced convulsions biphasically. Neuroscience. 2004;128(4):721-8. PMID: 15464280.

22.Polyakov NE, Leshina TV, Konovalova TA, Kispert LD. Carotenoids as scavengers of free radicals in a Renton reaction: antioxidants or pro-oxidants? Free Radic Biol Med. 2011;31(3):398-404. PMID: 11461778.

23.Patel $R$, Sesti F. Oxidation of ion channels in the aging nervous system. Brain Res. 2016;1639:174-85. doi: 10.1016/j. brainres.2016.02.046.

24.Patel R, Sesti F. Oxidation of ion channels in the aging nervous system. Brain Res. 2016;1639:174-85. doi: 10.1016/j. brainres.2016.02.046.

25.Erdman JW Jr, Smith JW, Kuchan MJ, Mohn ES, Johnson EJ, Rubakhin SS, Wang L, Sweedler JV, Neuringer M. Lutein and brain function. Foods. 2015;4(4):547-64. doi: $10.3390 /$ foods 4040547 .

26. Merkler $D$, Klinker $F$, Jürgens $T$, Glaser $R$, Paulus W, Brinkmann BG, Sereda MW, Stadelmann-Nessler C, Guedes RC, Brück W, Liebetanz D. Propagation of spreading depression inversely correlates with cortical myelin content. Ann Neurol. 2009;66(3):35565. doi: 10.1002/ana.21746.

27.Arredondo F, Echeverry $C$, Abin-Carriquiry $J A$, Blasina $F$, Antúnez $K$, Jones $D P$, Go YM, Liang YL, Dajas F. After cellular internalization, quercetin causes Nrf2 nuclear translocation, increases glutathione levels, and prevents neuronal death against an oxidative insult. Free Radic Biol Med. 2010;49(5):738-47. doi: 10.1016/j. freeradbiomed.2010.05.020.

28.Zargar S, Siddiqi NJ, Ansar S, Alsulaimani MS, El Ansary AK. Therapeutic role of quercetin on oxidative damage induced by acrylamide in rat brain. Pharm Biol. 2016;54(9):1763-7. doi: 10.3109/13880209.2015.1127977.

29.Guedes RCA, Amâncio-dos-Santos A, Manhães-de-Castro R, Costa-Cruz RRG. Citalopram has an antagonistic action on cortical spreading depression in wellnourished and early-malnourished adult rats. Nutr Neurosci. 2002;5(2):115-23. PMID: 12000081. 
30.Perez-Gutierrez RM, Muñiz-Ramirez A, Gomez YG, Ramírez EB. Antihyperglycemic, antihyperlipidemic and antiglycation effects of Byrsonima crassifolia fruit and seed in normal and streptozotocin-induced diabetic rats. Plant Foods Hum Nutr. 2010;65(4):3507. doi: 10.1007/s11130-010-0181-5.

\section{Acknowledgements}

CETENE (Centro de Tecnologias Estratégicas do Nordeste) for help in obtaining the extracts, and Dra. Luciana Lima for the polyphenols identification.

\section{Correspondence:}

Mariana Séfora Bezerra Sousa

Departamento de Nutrição, Centro de Ciências da Saúde, UFPE

Avenida Professor Moraes Rego, 1235

50670-901 Recife - PE Brasil

Tel.: (55 81)2126-8530

marianasefora@yahoo.com.br

Received: Feb 09, 2018

Review: Apr 08, 2018

Accepted: May 12, 2018
Conflict of interest: none

Financial sources: CNPq, FACEPE (APQ0484-2.07/15), and PROPESQ/UFPE (23076.048111/2014-22)

${ }^{1}$ Research performed at Laboratory of Neurophysiology, Department of Physiology and Pharmacology, Universidade Federal de Pernambuco (UFPE), Recife-PE, Brazil. Part of PhD degree thesis, Postgraduate Program in Nutrition, UFPE. Tutor: Dra. Ângela Amâncio dos Santos. 